\section{$\underset{\substack{\text { hommes } \\ \text { \& migrations }}}{ }$}

\section{Hommes \& migrations}

Revue française de référence sur les dynamiques

migratoires

1308 | 2014

Les Paris des migrants

\title{
Paris et ses migrants : dans les pas de Michelle Guillon
}

\section{Mathieu Delage}

\section{OpenEdition \\ Journals}

Édition électronique

URL : http://journals.openedition.org/hommesmigrations/2988

DOI : 10.4000/hommesmigrations.2988

ISSN : 2262-3353

Éditeur

Musée national de l'histoire de l'immigration

Édition imprimée

Date de publication : 1 octobre 2014

Pagination : 27

ISBN : 978-2-919040-29-2

ISSN : $1142-852 X$

\section{Référence électronique}

Mathieu Delage, "Paris et ses migrants : dans les pas de Michelle Guillon », Hommes \& migrations [En ligne], 1308 | 2014, mis en ligne le 01 octobre 2017, consulté le 24 septembre 2020. URL : http:// journals.openedition.org/hommesmigrations/2988; DOI : https://doi.org/10.4000/ hommesmigrations.2988 


\section{$>$ DANS LES PAS DE MICHELLE GUILLON}

Michelle Guillon est une des principales pionnières de l'étude de l'immigration dans la région parisienne. Professeure de géographie à l'université de Poitiers, chercheure emblématique du laboratoire Migrinter, longtemps codirectrice de la Revue européenne des migrations internationales, elle a participé à de nombreuses études fondatrices, souvent en collaboration avec d'autres chercheurs comme Gildas Simon, Véronique De Rudder, Isabelle Taboada-Leonetti, Maryse Tripier, Nicole Sztokman, Emmanuel Ma Mung, et d'autres encore. Elle a participé à l'émergence d'une géographie sociale de l'immigration dans la métropole parisienne, attentive à la relier aux divisions sociales de l'espace qui concernent tous les habitants. Sa thèse d'État, soutenue en 1992 à l'université Paris-l, intitulée “Étrangers et immigrés en Îlede-France" (560 p.), est une somme incontournable d'informations, restée hélas inédite, à un moment où déjà l'immigration commençait à faire l'objet d'amalgames et de simplifications outrancières dans certains discours nationalistes.

L'ouvrage est organisé en trois parties : un historique des deux siècles de migrations qui ont constitué la population de la région parisienne, une description démo-socio-économique des étrangers et les combinaisons de nationalités dans l'espace. L'analyse est fondée sur une exploitation longitudinale des recensements (de 1968 à 1990), traduite en de multiples cartes qui font sa richesse exceptionnelle, décortiquant les différentes formes de spatialisation, souvent décomposées par catégories (en fonction du sexe, de la catégorie socioprofessionnelle, du pays d'origine, etc.) et assorties d'une série de cartes typologiques (combinant des écarts à la moyenne de diverses variables). Complétée par une iconographie abondante et une bibliographie précieuse (de nombreux titres ont été oubliés depuis), cette exploration atteste le rôle de l'hétérogénéité du parc de logements, de la structure des emplois et de la variété des trajectoires migratoires dans la diffusion spatiale des ménages immigrés.

Ce sont les conditions de logement, et d'accès au logement, ainsi que le travail et l'accès au marché du travail qui constituent les deux fils directeurs. L'émergence politique de la "question immigrée" est liée aux conditions de logements qui sont réservés aux étrangers et à leur révélation à l'opinion publique dans les années 1970 : les incendies de baraques dans les bidonvilles de Champigny, de la Folie à Nanterre ou encore à Saint-Denis, Argenteuil, Montmagny. Les courants politiques de gauche et les mouvements humanitaires chrétiens commencent alors à défendre les droits et les conditions de vie des immigrés, cependant que d'autres courants vont saisir l'occasion pour s'opposer à l'immigration "sauvage". Dans les deux cas, "l'image des immigrés donnée alors par la presse et les discours politiques est celle de sous-prolétaires”, (p. 98). Et ce, alors même que l'analyse des positions socio-économiques (chapitre 6), beaucoup plus diversifiées que ne le laissait supposer la catégorie englobante "travailleurs immigrés", montrait que, "déjà à l'époque des grands flux, l'émigration de travailleurs n'était que rarement un exode de la misère" (p. 135). L'immigration de travail, maximale entre les recensements de 1968 et 1975, n'a pas fourni qu'une main-d'œuvre d'appoint : sans elle, "le glissement vers le tertiaire d'une partie de la main-d'œuvre française" n'aurait pas été possible.

L'historique de ce peuplement montre que la spécificité de la région francilienne est systématiquement corrélée à l'évolution des politiques de contrôle des entrées et à l'évolution des trajectoires migratoires (de plus en plus qualifiées et venant de pays de plus en plus divers). De même, l'auteure montre les écarts entre l'évolution des chiffres (tassement précoce de la croissance de la population étrangère) et la perception par l'opinion et les médias. C'est grâce à toutes ces confrontations analytiques qu'elle fournit des outils précieux et toujours valables pour combattre les idées reçues.

/// Michelle Guillon, "Étrangers et immigrés en île-de-France", thèse d'État, université Paris-I, 1992, extraits de la conclusion, pp. 479-481. 